\title{
Detection and Enumeration of Listeria monocytogenes in Fresh Cut Vegetables Using MPN-Real-Time PCR
}

P. Russo ${ }^{1, a}$, G. Botticella ${ }^{1, a}$, M.L. Amodio ${ }^{1}$, G. Colelli ${ }^{1}$, M. Cavaiuolo ${ }^{2}$, A. Ferrante ${ }^{2}$, S. Massa ${ }^{1}$, G. Spano ${ }^{1}$ and L. Beneduce $\mathrm{e}^{1, \mathrm{~b}}$

${ }^{1}$ Dept. of Agricultural, Food and Environmental Sciences, University of Foggia, via Napoli 25, 71122 Foggia, Italy

${ }^{2}$ Dept. Agricultural and Environmental Sciences - Production, Landscape, Agroenergy, University of Milano, Italy

Keywords: fresh cut, Listeria monocytogenes, DNA extraction, MPN, qPCR

\begin{abstract}
Listeria monocytogenes is a gram positive, rod shaped, pathogenic bacterium, causative agent of a severe infection generally known as listeriosis. Packaging and storage conditions of fresh cut vegetables may favour the growth of this psychrotrophic pathogen leading to potential health threat. Detection and enumeration of $L$. monocytogenes in concentrations up to $10^{3} \mathrm{CFU} / \mathrm{g}$, usually implies use of the most-probable-number technique (MPN) which may take up to seven days for verified identification of the pathogen. We developed a fast and reliable protocol combining MPN with a Real-Time quantitative PCR (qPCR) approach. Samples of fresh cut salads ( $25 \mathrm{~g}$ ) purchased at local shops were spiked with 1 to $10^{5} \mathrm{CFU} / \mathrm{g}$ of L. monocytogenes. Samples were homogenized, and triplicate series of tubes containing $10^{-5}$ to $10 \mathrm{~g}$ of food were incubated in Fraser broth at $30^{\circ} \mathrm{C}$ for $48 \mathrm{~h}$ for standard MPN analysis. After incubation, broth samples were taken from each tube and DNA was extracted. DNA from enrichment tubes was used as template in a qPCR assay targeting a $64 \mathrm{bp} h l y A$ gene sequence of $L$. monocytogenes. Results of this assay were than compared with those of standard MPN analysis and a complete accordance was observed. Furthermore, we tested an enrichment free approach using the same qPCR assay. Samples were prepared as described for MPN-qPCR while DNA extraction was performed prior to enrichment of inoculated salads. This approach allowed us to identify $L$. monocytogenes in samples spiked with $10-10^{5}$ CFU/g. The whole process, including DNA extraction, required less than four hours, thus providing a fast and reliable tool for detection of $L$. monocytogenes in fresh cut vegetables.
\end{abstract}

\section{INTRODUCTION}

Listeria monocytogenes is a rod shaped, non spore-forming, Gram positive facultative anaerobic bacterium (Seeliger and Jones, 1986). L. monocytogenes is the causative agent of listeriosis, a severe, potentially fatal infection. During the early stages, human listeriosis often displays non-specific flu-like symptoms and gastroenteritis. However, if listeriosis is not medically treated, it can develop into septicaemia, meningitis, encephalitis, abortion and, in about $30 \%$ of cases, death (Liu, 2006). A wide range of foods have been associated to outbreaks of listeriosis including several ready-toeat (RTE) foods and fresh-cut products (Gillespie et al., 2010; Little et al., 2010; Gaul et al., 2013). L. monocytogenes is a pathogen of particular concern for safety of fresh cut products as it grows across a broad $\mathrm{pH}$ range (4.3-9.8) and temperatures around $4^{\circ} \mathrm{C}$ (Ghandi and Chikindas, 2007). Moreover, it can grow in aerobic modified atmospheres also with competitive microorganisms (Wimpfheimer et al., 1990). It is commonly accepted that the minimal infectious dose for L. monocytogenes is at least $100 \mathrm{CFU}$ per gram of food (Nørrung, 2000). However, depending on both the food considered and food safety legislations, accepted concentrations of L. monocytogenes range from 0 to

\footnotetext{
a Authors contributed equally to this work.

b tel: +39(0)881 589303, fax: +39(0)881 740211, e-mail: luciano.beneduce@unifg.it
} 
100 CFU/g (Yang et al., 2007; Commission Regulation (EC) No. 2073/2005). Enumeration of L. monocytogenes in food matrices is usually carried out by the Most Probable Number (MPN) method which is laborious and time-consuming (5-10 days), as it requires preparation of replicated dilution series in selective enrichment broth, followed by plating on selective agar and tests for species identification (Berrada et al., 2006; Churchill et al., 2006). The development of fast and reliable detection and quantification methods for L. monocytogenes is important for verifying food safety and prevention of listeriosis. During the past decade a number of PCR-based methods, targeting mostly virulence factors and 16srRNA genes, have been proposed for detection and/or quantification of L. monocytogenes in foods (Pan and Breidt, 2007; O'Grady et al., 2008; Rantsiou et al., 2008). The aim of this study was to evaluate a combination of MPN and qPCR for quantification in fresh-cut vegetables along with development of a simple and fast protocol for detection and enumeration of L. monocytogenes from minimally processed vegetables relying on qPCR only.

\section{MATERIALS AND METHODS}

\section{Food Samples}

Minimally processed fresh cut vegetables (arugula, salad mixes) were randomly purchased at local shops in Foggia (Italy) and stored at $4{ }^{\circ} \mathrm{C}$.

\section{Bacterial Strains, Media and Cultures}

A total of 4 bacterial strains were used, including Listeria monocytogenes (CECT4031), Listeria ivanovii (IZSPB48), Listeria innocua (IZSPB45) and Lactobacillus plantarum (WCSF1). All strains were grown overnight in TSB broth (Oxoid, Hampshire, $\mathrm{UK})$ at $37^{\circ} \mathrm{C}$, without agitation.

\section{Artificial Contamination of Samples}

All tests were performed on artificially contaminated fresh cut vegetables. For both, L. monocytogenes and negative controls, $25 \mathrm{~g}$ samples of food were spiked with $10^{0}$ to $10^{5}$ cells $/ \mathrm{g}$. Bacterial cells were suspended in $1.0 \mathrm{ml}$ TSB broth (Oxoid, Hampshire, UK).

\section{DNA Isolation and Analysis}

Three different DNA extraction protocols were evaluated, in order to select the most suitable one, on the basis of cost, time, yield, quality and personnel skills required.

1. DNeasy Blood and Tissue Kit (Qiagen, Milano, IT). The extraction was performed following the manufacturer's protocol for Gram-positive. Slight modifications were: adjustment to $40 \mathrm{~min}$ for lysozyme and proteinase $\mathrm{K}$ digestion, double elution of DNA with 100 and $50 \mu 1$ aliquots of elution buffer.

2. Phenol-Chloroform Extraction. The organic extraction was performed according to standard method (Sambrook and Russel, 2001).

3. Power Soil DNA Isolation Kit (Mo-Bio, Carlsbad, CA, USA). Extraction was carried out following manufacturer's instruction. Mechanical lysis was performed using a Mini bead beater (Biospec products, Bartlesville OK, USA) for $30 \mathrm{~s}$ at half power.

The amount and purity of DNA were assessed by measuring absorbance at $260 \mathrm{~nm}$ (concentration) and the ratio between absorbance at 260 and $280 \mathrm{~nm}$ (purity) using a BioTek Eon spectrophotometer (BioTek, VT, USA). DNA purity was considered satisfactory when the A260/A280 ratio was $>1.50$. The degradation level of the extracted DNA was evaluated by electrophoresis in agarose gel $(1 \% \mathrm{w} / \mathrm{v})$. All DNA samples were stored at $-20^{\circ} \mathrm{C}$ prior to use.

\section{MPN Enumeration of Listeria monocytogenes}

Inoculated vegetable (rocket salad) samples $(25 \mathrm{~g}$ ) were added to $225 \mathrm{ml}$ of Fraser broth (Oxoid, Hampshire, UK) in sterile filter bags (BagFilter ${ }^{\circledR}$, Interscience, Ile de 
France, FR) and homogenized in a stomacher (Bag Mixer ${ }^{\circledR}$, Interscience) for 2 min. Bags were incubated for $4 \mathrm{~h}$ at $37^{\circ} \mathrm{C}$ and Fraser selective supplement was successively added (Oxoid, SR0156E). Triplicate series of tubes were prepared to contain 10, 1, 0.1, 1.10-2, $1 \cdot 10^{-3}, 1 \cdot 10^{-4}$ and $1 \cdot 10^{-5}$ grams of food. Tubes were incubated for $44 \mathrm{~h}$ at $30^{\circ} \mathrm{C}$. Aliquots $(100 \mu \mathrm{l})$ of enrichment broth were taken from tubes containing presumptive Listeria spp. (dark colour) and streaked on plates containing Oxford agar (Oxoid, Hampshire, UK) and PALCAM agar (Oxoid, Hampshire, UK). Plates were incubated at $37^{\circ} \mathrm{C}$ for $48 \mathrm{~h}$ and five typical colonies were picked for purification on TSA $+0.6 \%$ yeast extract plates (Oxoid, Hampshire, UK). Plates were incubated for $24 \mathrm{~h}$ at $37^{\circ} \mathrm{C}$ and Gram positive, catalase positive colonies were streaked on Blood agar $\left(37^{\circ} \mathrm{C}, 24 \mathrm{~h}\right)$. Hemolytic colonies were identified as Listeria monocytogenes using API Listeria strips (Biomerieux, Marcy l'Etoile, FR). MPN was calculated using MPN Calculator Build 23 software (Mike Curiale).

\section{QPCR Assays}

All qPCR assays were performed on an AB 7300 Real Time PCR System (Life Technologies, Monza, ITA). Target genes, primers and probes employed are listed in Table 1. Four different assays were tested: 16S rRNA, hlyA (1), hlyA (2) and iap. All reactions were carried out using iTaq SYBR green Supermix with ROX (BIO-RAD) or 1 iTaq Universal probes Supermix (BIO-RAD) depending on the employed chemistry. Reagent concentration and amplification cycles are reported in the reference papers listed in Table 1.

\section{RESULTS AND DISCUSSION}

\section{DNA Extraction}

The first part of the present study was focused on the individuation of a suitable protocol for bacterial DNA extraction from fresh cut vegetables. Several parameters were considered. It was necessary to identify a procedure which could guarantee a good DNA yield combined with adequate purity and, especially, the absence of PCR inhibitors such as complex polysaccharides. Furthermore, we needed a simple, time efficient, possibly low cost procedure. Finally, possible manipulation of toxics had to be taken into account. Three different extraction procedures were evaluated, including two commercial kits (Qiagen Blood and Tissue, Mo-Bio Power Soil) and a Phenol-Chloroform extraction. DNA extraction was performed on artificially inoculated samples incubated at $37^{\circ} \mathrm{C}$ for $8 \mathrm{~h}$ using Listeria monocytogenes as a test organism (see Materials and methods section). Purity and concentration of DNA (quadruplicate samples) was evaluated with a BioTek Eon spectrophotometer (BioTek, Winooski, VT) as described in the previous section. All the extraction methods guaranteed adequate yield and purity (Table 2). However, phenolchloroform method was discarded at this stage due to major drawbacks such as laboriousness, time required for extraction, necessity to store and manipulate significant amounts of toxic compounds. The eventual degradation of DNA extracted with Mo-Bio Power soil and Qiagen Blood and Tissue kits was evaluated by agarose gel electrophoresis. In both cases no significant degradation was observed (data not shown). Nonetheless Qiagen Blood and Tissue kit appears to be more suitable for our purposes because either assuring more than acceptable purity and yield of DNA, or less expensive and time consuming than Mo-Bio Power Soil Kit.

\section{QPCR Assays}

QPCR assay targeting L. monocytogenes $16 \mathrm{~S}$ rRNA gene was initially chosen as it was assumed that presence of a multi-copy target sequence would enhance assay sensitivity. The assay was based on the use of SYBR green rather than fluorescent probes in order to reduce cost per reaction. Assay specificity was tested against DNA extracted from L. monocytogenes, L. innocua, L. ivanovii and L. plantarum (used as negative control strain). The assay showed the expected signal in the case of $L$. monocytogenes and 
no signal in the case of the Lactobacillus plantarum strain. However, it lacked of specificity as a signal was also observed in the case of L. innocua and L. ivanovii. Due to this evidence, the assay was discarded and a SYBR green qPCR assay targeting $h l y A$ gene ( $h l y A(1)$, see previous section) was tested. This test was expected to improve specificity as it was directed to detect a specific virulence related gene. However, even in this case, similar results were observed, with positive signal generated also with nonmonocytogenes DNA (data not shown). Therefore, this assay was also discarded. Due to the unsatisfactory results obtained, we decided to perform further tests employing probebased assays in order to identify an adequate specificity. Primers and probes targeting iap gene designed by Hein et al. (2001) were chosen for this assay. The assay was tested against the strains previously analyzed using the same protocols. In this case, the assay proved adequately specific, and only positive signal for L. monocytogenes strains were detected. Nonetheless, the assay was discarded as it was unsuitable for quantification purposes because of high serovar-related variability of results (data not shown). A second probe-based assay ( $h l y A(2)$, see previous section) was then tested. Primers and probes from Rodríguez-Lazaro et al. (2004) were adopted. The assay based on these oligonucleotides correctly identified L. monocytogenes in all of our tests while showing no signal in the case of non- $L$. monocytogenes strains. In Figure 1 the specificity of different qPCR assays are reported. Detection limits of the qPCR assay were successively investigated. For this purpose, duplicate serial dilutions of $L$. monocytogenes DNA were subjected to qPCR and a standard curve was constructed. The standard curve showed a linear relationship (spanning over 7 logs) between log input DNA and threshold cycle. The slope of the curve was -3.45 and the square regression coefficient was $\mathrm{R}^{2}=0.998$. Detection limit was 0.28 picograms of DNA per reaction. These data led us to consider this qPCR assay suitable for development of MPN-qPCR and enrichment free enumeration protocols.

\section{MPN-qPCR}

MPN experiments were performed as illustrated in the Materials and Methods section. For DNA extraction, enrichment tube aliquots $(1 \mathrm{ml})$ were taken from both positive and negative enrichment tubes. Then detection of L. monocytogenes using hlyA(2) qPCR protocol was performed. All of the tubes which tested positive after $48 \mathrm{~h}$ incubation in Fraser broth were eventually confirmed positive by conventional identification tests. In all of these samples L. monocytogenes was also detected using our qPCR protocol, while negative enrichment tubes gave negative results both in the qPCR assay and conventional methods. These findings illustrate complete accordance between our assay and MPN enumeration (Table 3). Our protocol can be employed to shorten MPN enumeration of L. monocytogenes from circa 5-10 days to $48 \mathrm{~h}$ with a faster and reliable confirmation of positive samples.

The development of a shorter MPN protocol for detection of L. monocytogenes may prove useful for assessing food safety due to its rapidity and sensitivity. This technique is also suitable for automation and high throughput applications, yet validation is necessary to adopt these molecular protocols in the food industry. Further development of the proposed qPCR based techniques includes use of propidium monoazide or similar compounds (i.e., etidium monoazide) in order to quantify viable cells exclusively.

\section{ACKNOWLEDGEMENTS}

This work was partially funded by PON 01_01435 OFRALSER, national research project and UE $7^{\text {th }}$ framework programme project QAFETY (KBBE.2011.2.4-01, project nr.289719).

\section{Literature Cited}

Seeliger, H.P.R. and Jones, D. 1986. Genus Listeria. p.1235-1245. In: P.H.A. Sneath, N.S. Mair, M.E. Sharpe and J.G. Holt (eds.), Bergey's Manual of Systematic Bacteriology, volume 2. Williams \& Wilkins, Baltimore. 
Liu, D. 2006. Identification, subtyping and virulence determination of Listeria monocytogenes, an important foodborne pathogen. J. Med. Microbiol. 55:645-659.

Gillespie, I.A., Mook, P., Little, C.L., Grant, K. and Adak, G.K. 2010. Listeria monocytogenes infection in the over-60s in England between 2005 and 2008: a retrospective case-control study utilizing market research panel data. Foodborne Path. Dis. 7:1373-1379.

Little, C.L., Pires, S.M., Gillespie, I.A., Grant, K. and Nichols, G.L. 2010. Attribution of human Listeria monocytogenes infections in England and Wales to ready-to-eat food sources placed on the market: adaptation of the Hald Salmonella source attribution model. Foodborne Path. Dis. 77:749-756.

Gaul, L.K., Farag, N.H., Shim, T., Kingsley, M.A., Silk, B.J. and Hyytia-Trees, E. 2013. Hospital-acquired listeriosis outbreak caused by contaminated diced celery - Texas, 2010. Clin. Infect. Dis. 56:20-26.

Gandhi, M. and Chikindas, M.L. 2007. Listeria: a foodborne pathogen that knows how to survive. Int. J. Food Microbiol. 113:1-15.

Wimpfheimer, L., Altman, N.S. and Hotchkiss, J.H. 1990. Growth of Listeria monocytogenes Scott A, serotype 4 and competitive spoilage organisms in raw chicken packaged under modified atmospheres and in air. Int. J. Food Microbiol. 11:205-214.

Nørrung, B. 2000. Microbiological criteria for Listeria monocytogenes in foods under special consideration of risk assessment approaches. Int. J. Food Microbiol. 62:217221.

Yang, H., Qu, L., Winbrow, A.N., Jiang, X. and Sun, Y. 2007. Rapid detection of Listeria monocytogenes by nanoparticle based immunomagnetic separation. Int. J. Food Microbiol. 118:132-138.

Commission Regulation (EC) No. 2073/2005 of 15 November 2005 on microbiological criteria for foodstuffs.

Berrada, H., Soriano, J.M., Picó, Y. and Mañes, J. 2006. Quantification of Listeria monocytogenes in salads by real time quantitative PCR. Int. J. Food Microbiol. 107:202-206.

Churchill, R.L.T., Lee, H. and Hall, J.C. 2006. Detection of Listeria monocytogenes and the toxin listeriolysin O in food. J. Microbiol. Meth. 64:141-170.

Pan, Y. and Breidt, F.J. 2007. Enumeration of viable Listeria monocytogenes cells by Real-Time PCR with propidium monoazide and ethidium monoazide in the presence of dead cells. Appl. Environ. Microbiol. 73:8028-8031.

O'Grady, J., Sedano-Balba, S., Maherb, M., Smith, T. and Barry, T. 2008. Rapid realtime PCR detection of Listeria monocytogenes in enriched food samples based on the ssrA gene, a novel diagnostic target. Food Microbiol. 25:75-84.

Rantsiou, K., Alessandria, V., Urso, A., Dolci, A. and Cocolin, L. 2008. Detection, quantification and vitality of Listeria monocytogenes in food as determined by quantitative PCR. Int. J. Food Microbiol. 121:99-105.

Sambrook, J. and Russell, D.W. 2001. Commonly used techniques in molecular cloning. In: Cold Spring Harbor Laboratory Press (eds.), Molecular Cloning, Volume 3, $3^{\text {rd }}$ edition. NY, USA.

Nogva, H.K., Rudi, K., Naterstad, K., Holck, A. and Lillehaug, D. 2000. Application of 5 '-nuclease PCR for quantitative detection of Listeria monocytogenes in pure cultures, water, skim milk, and unpasteurized whole milk. Appl. Environ. Microbiol. 66:42664271.

Hein, I., Klein, D., Lehner, A., Bubert, A., Brandl, E. and Wagner, M. 2001. Detection and quantification of the iap gene of Listeria monocytogenes and Listeria innocua by a new real-time quantitative PCR assay. Res. Microbiol. 152:37-46.

Rodríguez-Lazaro, D., Hernandez, M., Scortti, M., Esteve, T., Vazquez-Boland, J.A. and Pla, M. 2004. Quantitative detection of Listeria monocytogenes and Listeria innocua by Real-Time PCR: assessment of hly, iap, and lin02483 targets and AmpliFluor technology. Appl. Environ. Microbiol. 70:1366-137. 
De Oliveira, M.A., Abeid Ribeiro, E.G., Morato Bergamini, A.M. and Pereira De Martinis, E.C. 2010. Quantification of Listeria monocytogenes in minimally processed leafy vegetables using a combined method based on enrichment and 16S rRNA realtime PCR. Food Microbiol. 27:19-23. 


\section{$\underline{\text { Tables }}$}

Table 1. QPCR assays, primers and probes.

\begin{tabular}{|c|c|c|c|c|c|}
\hline $\begin{array}{l}\text { Target } \\
\text { gene }\end{array}$ & $\begin{array}{c}\text { Forward primer } \\
\left(5^{\prime}-3{ }^{\prime}\right)\end{array}$ & $\begin{array}{c}\text { Reverse primer } \\
\left(5^{\prime}-3^{\prime}\right)\end{array}$ & $\begin{array}{c}\text { Probe } \\
\text { (5'FAM-TAMRA3') }\end{array}$ & $\begin{array}{l}\text { Fragment } \\
\text { size (bp) }\end{array}$ & Reference \\
\hline 16S rRNA* & CACGTGCTACAATGGATAG & AGAATAGTTTTATGGGATTAG & None & 70 & $\begin{array}{l}\text { de Oliveira } \\
\text { (2010) }\end{array}$ \\
\hline$h l y A(1)^{*}$ & TGCAAGTCCTAAGACGCCA & CACTGCATCTCCGTGGTATACTAA & None & 113 & $\begin{array}{l}\text { Nogva } \\
(2000)\end{array}$ \\
\hline$h l y A(2)^{+}$ & CATGGCACCACCAGCATCT & ATCCGCGTGTTTCTTTTCGA & CGCCTGCAAGTCCTAAGACGCCA & 64 & $\begin{array}{l}\text { Rodriguez } \\
\quad(2004)\end{array}$ \\
\hline $\operatorname{Iap}^{+}$ & CTAAAGCGGGAATCTCCCTT & CCATTGTCTTGCGCGTTAAT & CTTCTGGCGCACAATACGCTAGCACT & 174 & Hein $(2001)$ \\
\hline
\end{tabular}

*SYBR green, ${ }^{+}$TaqMan.

Table 2. DNA extraction methods comparison.

\begin{tabular}{lccccc}
\hline Extraction method & Cost per reaction $(€)$ & Time $(20$ sample-run) & Yield $(\mathrm{ng} / \mu \mathrm{l})$ & Purity $\mathrm{A}_{260} / \mathrm{A}_{280}$ & Manipulation of toxics \\
\hline MoBio kit & 7.00 & $2.2 \mathrm{~h}$ & $75.13 \pm 8.46$ & $>1.6$ & Not significant \\
Qiagen kit & 5.00 & $1.3 \mathrm{~h}$ & $64.85 \pm 4.89$ & $>1.6$ & Not significant \\
Phen/chlor & 0.50 & $3 \mathrm{~h}$ & $87.17 \pm 6.74$ & $>1.6$ & Significant \\
\hline
\end{tabular}

Table 3. MPN test results and concordance with qPCR.

\begin{tabular}{lcc}
\hline Inoculum $(\mathrm{CFU} / \mathrm{g})$ & MPN $(\mathrm{CFU} / \mathrm{g})$ & \% of tubes confirmed positive by qPCR \\
\hline 1 & $0.93(0.23-3.80)$ & 100 \\
10 & $4.3(1-18)$ & 100 \\
100 & $43(10-180)$ & 100 \\
1000 & $564(155-1890)$ & 100 \\
\hline
\end{tabular}




\section{Figures}

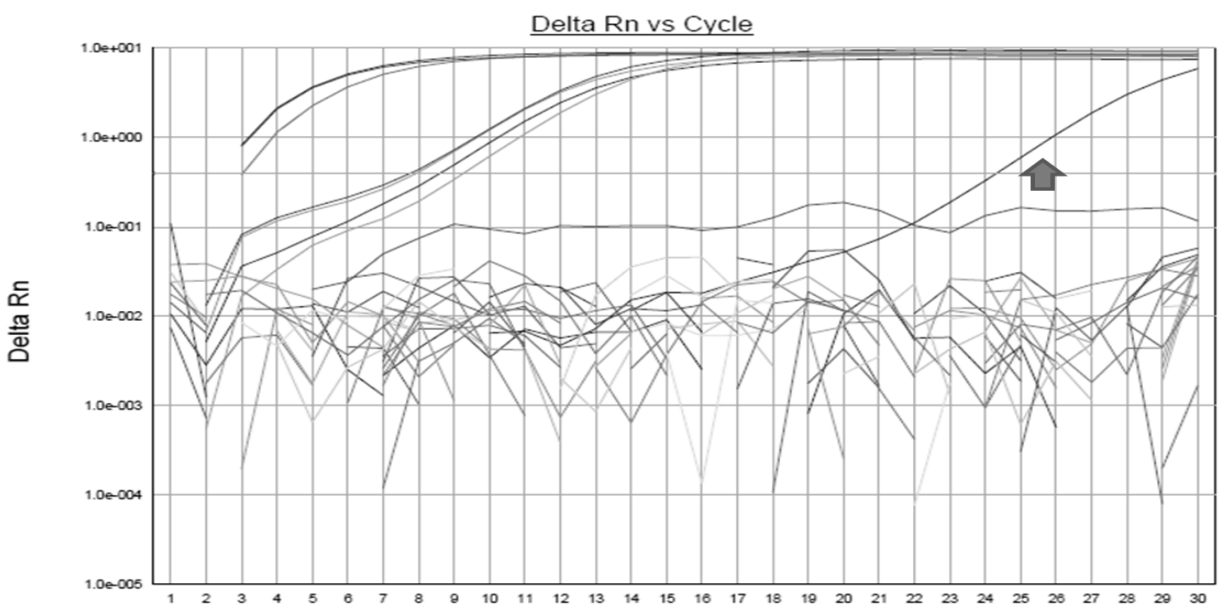

A

Cycle Number

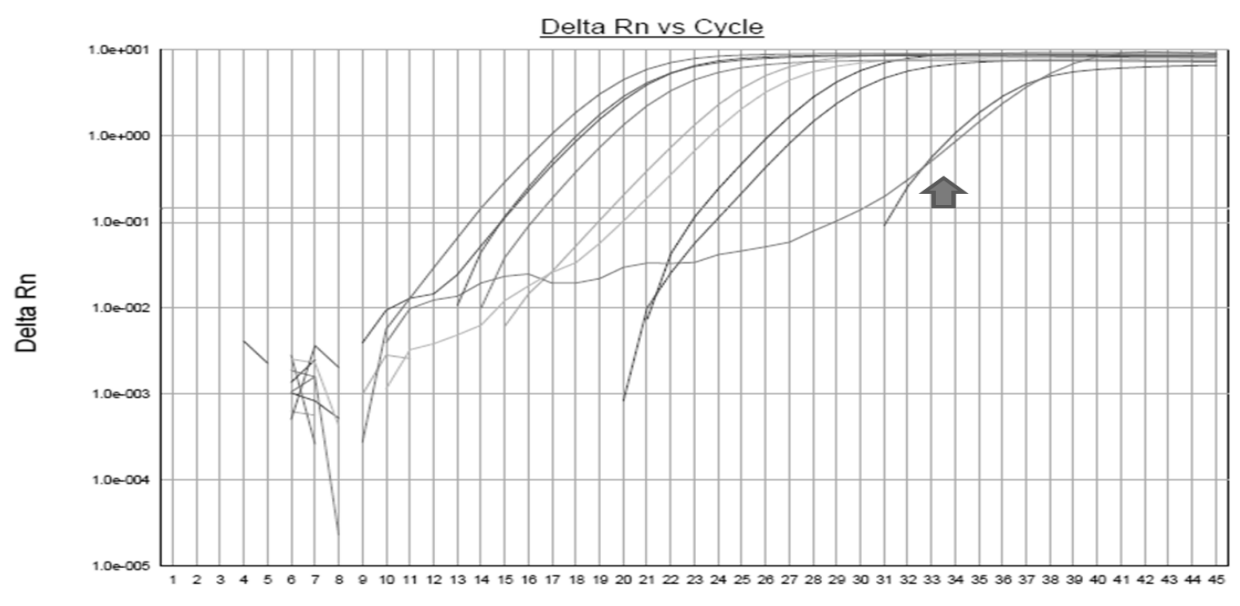

B

Cycle Number

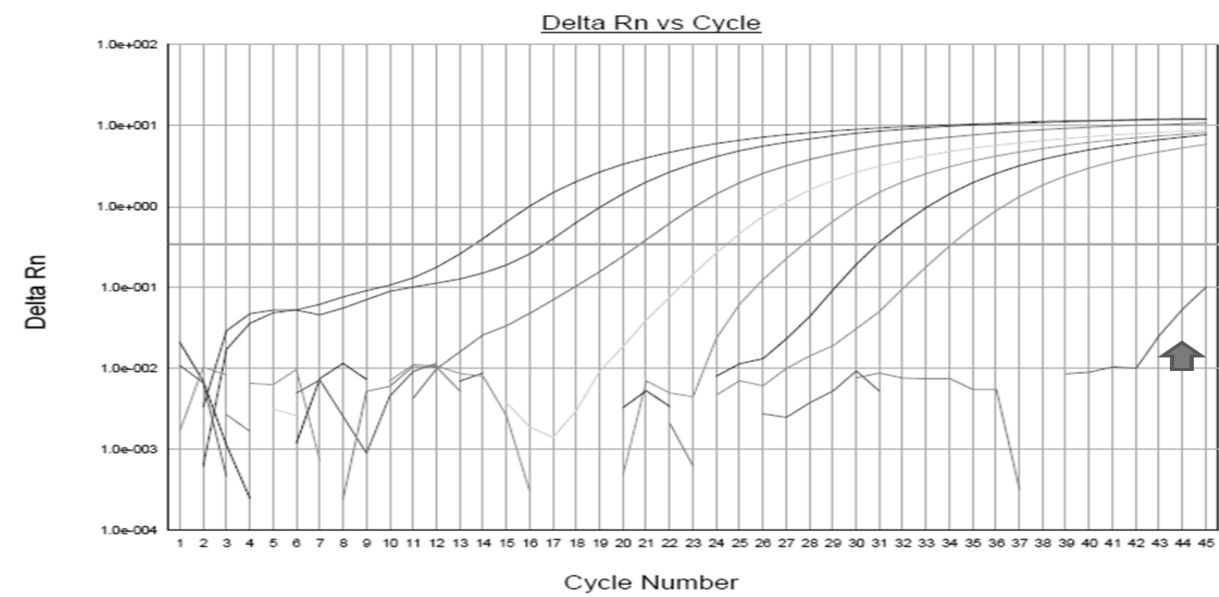

C

Cycle Number

Fig. 1. QPCR amplification for L. monocytogenes CECT 4031, Listeria ivanovii (IZSPB48) and Listeria innocua (IZSPB45) by using as target gene 16S rRNA (A) and $h l y A$ without (B) or with probe (C). Arrows indicate non-monocytogenes Listeria spp. strains. 